\title{
Optical Characteristics of Oil Palm Fresh Fruits Bunch (FFB) Under Three Spectrum Regions Influence for Harvest Decision
}

\author{
Dinah Cherie ${ }^{\# *}$, Sam Herodian*, Usman Ahmad*, Tineke Mandang", Muhammad Makky ${ }^{*}$

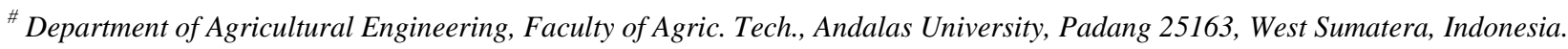 \\ E-mail: cherie.dinah@yahoo.com
}

* Department of Agricultural Engineering and Bio systems, Faculty of Agric. Tech., Bogor Agricultural University, Bogor 16680, Indonesia.

\begin{abstract}
In current practice, appearance was used to determine ripeness for oil palm fresh fruits bunch (FFB), that accompanied by detachment of fruit-lets from the bunch. The FFB from marihat clone harvested at five ripeness stages, under ripeness (F0), ripeness (F1, F2, F3), and over ripeness (F4). At every ripeness stages, differences of oil content and pigment accumulation were observed on the bunch. All samples recorded using a digital camera (10 MPixels) from 2, 7, 10, and 15 meter distance, simulating variation of light intensity upon recording. During image recording, three lighting were used, namely ultraviolet lamp (320-380 $\mathrm{nm})$, visible light lamp $(400-700 \mathrm{~nm})$ and infrared lamp $(720-1100 \mathrm{~nm})$, all have similar power output of 600watt. Camera point of view was set to cover a square area of $12,5 \mathrm{~cm}$ by $12,5 \mathrm{~cm}$ of the frontal area of FFB, each picture produced has 3888 by 2952 pixel. Image processing software created to extract digital RGB information from the images, and displayed the information in histogram. From the experiment, it was observed that the changes of intensity influence the RGB value of recorded image with reverse correlation, and longer wave light spectrum produce smaller RGB value. The correlation model among image recording distance and RGB of the image display similar nature. From three color channels, G_mean represents better correlation for sample's oil content determination. Using UV and visible lighting, the FFB samples may be determined for harvest decision, up to seven meter observation distance.
\end{abstract}

Keywords — Lighting spectrum, Image processing, Oil content, Imaging.

\section{INTRODUCTION}

Exporting oil palm products are among the key elements for Indonesian to generate their foreign exchange revenues [1-2]. By 2013, Indonesia export of palm oil and its derivatives make up $77.13 \%$ of country's agricultural effluent [3] and top \$ US 19 billion from export revenue [4]. Global demand and the spike in price, transform this product into main commodity, especially after Indonesian export of oil palm surpass Malaysia in 2006, and became the world top producer and exporter [2].

Beginning in 1997, a research by Indonesian Oil Palm Research Institute (IOPRI) identified significant potential revenue loss in most of Indonesian oil palm plantation, mainly due to inappropriate harvesting practice of fresh fruits bunch (FFB) [5]. When harvesting performed, the labor misjudged raw or unripe fresh fruit bunches (FFBs) and cropped it, while in other cases, ripe FFBs were missed harvested. Both mistakes account as plantations losses, and attain to more than 15 percent nationally [5]. Given the condition, it is necessary to explore the way of correct identification of oil palm FFB upon harvest. During ripening, oil palm FFB changes physiologically, and observed through the shift on their skin color due to pigment transformation and accumulation [1-2, 6-10]. However, human visual identification of color was subjective and prone to mistake due to mental and physical influences [11-13].

Current technologies enable the use of photosensitiveelectro sensor devices to correctly measured the fruits color and monitor its physiological-related developments [14-16]. Application of such technologies for FFB quality inspections have been done in previous studies [1-2, 9-22]. However, these studies emphasized post-harvest condition of oil palm FFB prior to milling process, and to the best of our knowledge, there hasn't any studies that utilize imaging technology for oil palm FFB quality determination prior to harvest.

Color-based and non-destructive quality inspections for agricultural products, i.e. fruits, generally performed by rapid, low-cost, and robust photosensitive-electro sensor imaging devices, such as digital camera [1-2, 9-16]. The device, accompanied by image processing software, became main choice for researchers, since it delivered consistent observations results [11-13]. The information stored in the recorded image can be extracted by the processing software 
and being used to make decision, especially related to the quality of the samples $[11,13]$. However, since the device work by sensing incoming light reflected from the samples, spectrum and intensity of the light influence the imaging results, thus there may be alteration of information stored in the recorded images [11-13, 22-23]. Changes of information in the recorded image can be seen from differences in composition of red-green-blue (RGB) value and apparent in the image's color histogram [24]. Therefore, the influence of light spectrum and intensity upon oil palm FFB quality inspections through imaging technique should be studied in advance.

Fruit ripening is a physiological process characterized by discoloration [14-16], and for oil palm FFB, correlated with the accumulation of oil in the mesocarp and kernels [11-13]. Thus, the oil content of FFB can be associated with its color display [1-2, 9, 11-13, 17-23]. Along with the physiological cycle, the FFB ripening process will reach its optimum point when the oil content in the mesocarp and kernels approaching to maximum level. Afterward, the degradation process commences, clearly identified by accelerating number of detached fruits from their bunch. Consequently, the FFB should be harvested at this optimum point.

The objective of this study is to observe changes of color properties from images of FFB at different ripeness stages, when recorded under different light level and spectrum ranges. The information will be used to correlate the RGB information for determining the accumulation of oil in FFB and harvest decisions

\section{MATERIALS AND METHODS}

The study performed on May 2013. The samples were oil palm fresh fruits bunch (FFB) of tenera variety from Marihat clone, grown in private company plantations in Bulik, Pangkalan Bun district, Central Kalimantan province, Indonesia $\left(2^{\circ} 05^{\prime} \mathrm{N}, 111^{\circ} 15^{\prime} \mathrm{E}\right)$. All samples were taken from 8 years plants. The area is $20-50 \mathrm{~m}$ above sea level, relatively flat plains with undulating transitions between 0 to $25 \%$. Annual rainfall range between $2000-2500 \mathrm{~mm}$ per year, and air temperature and humidity were 23 to $32{ }^{\circ} \mathrm{C}$ and 81 to $92 \%$ respectively.

Each FFB sample was first inspected by three expert panelists, where its ripeness determined based on the number of the detached fruitlet from the bunch and its fruits coloration. It was then harvested and cleaned from dirt and fiber, and then it was taken to the special room for imaging. The room was $17 \mathrm{~m}$ length long and three meter wide, and insulated from outside light. The wall painted with black color, and the room temperature maintained at $18{ }^{\circ} \mathrm{C}$ using air conditioner. Low room temperature intends to delay degradation process of oil in the fruits, which accelerated after harvested [25]. Different lamps were used to simulate FFB response under ultraviolet-visible-infrared radiation.

For recording the FFB images, two types of lamps were used, first an ultraviolet (UV) lamps which emitted light spectrum of 320-380 nm, and secondly a halogen lamps which emitted electromagnetic spectrum of visible light region (400-700 nm) and infrared (720-1100 nm). Both lamps have similar power output of 600 watt. Ultraviolet light used in order to determine the optical response of FFB through its surface light reflection under UV spectrum.
Whereas the halogen lamps be used to observe FFB optical response under visible light and Infrared (IR) spectrum. The fruits color of the FFB influenced by the composition of chlorophyll and carotene pigments in their skin. These two pigments have different response when illuminated under $\mathrm{UV}$, visible, and IR light. The properties related to the light absorption criteria of the pigment [12].

\section{A. Ultraviolet light FFB imaging}

The FFB placed on a flat table with fully black background on the rear-center of the room, and then lighted using a pair of 300 watts UV lamps with wavelength properties of 320-360 nm. The lamps positioned $1 \mathrm{~m}$ away facing the FFB, and lamp-FFB-camera position formed a $45^{\circ}$ line. A camera (EOS 60D, Canon, Japan), placed facing the FFB with lens positioned horizontally towards the focalcenter of the sample, used to record the FFB image. The Camera lens has 75-1300 mm focal length and 2.8 apertures (f) size, and the camera sensor has 10 million pixels resolution. The camera shutter speed was set to 0.8 second, and the sensor light sensitivity (ISO) was set to 1600 . Camera auto white balance program configured to be used under florescence light and the camera's field of view was set accordingly in order to cover frontal-center section of the FFB with an area of $0,125 \mathrm{~m} \mathrm{x} 0,125 \mathrm{~m}$. The FFB image subsequently recorded from a distance of two, seven, 10, and 15 meter, by moving the camera rearward, straight away from the sample. Every recording replicated three times, and the information from these three images was inputted to the image processing software.

\section{B. Visible light FFB imaging}

For recording the FFB image under visible light, the UV lamps replaced with a pair of 300 watt halogen lamps. Other FFB imaging configuration remained the same, however, to compensate the different nature of visible light with UV, the camera configurations modified accordingly. The camera ISO and shutter speed used in this imaging were set to 100 and 1/60 sec respectively, and the camera auto white balance program configured to compensate image recording under incandescent light.

\section{Near infrared light FFB imaging}

Experiment configuration for recording FFB image under IR light remain the same with imaging setup under visible light. However, to let the camera sensor captured only IR light reflected from the FFB, a special light filter was placed in front of the lens, ensuring only light spectrum with more than $720 \mathrm{~nm}$ wavelength passing the filter onto the camera sensor.

The Bayer filter mosaic layer on camera sensor formed a color filter array arranging red-green-blue (RGB) color for the sensor. This particular arrangement of Bayer filter mosaic layer color is used to create a color image, from most single-chip digital image sensors, particularly in digital cameras. The color image produced from the combination of RGB values in each pixel in the image. Therefore, even though UV and IR are monochromatic lights, every FFB image produced under these two lighting conditions remain a color image, and have RGB values in every pixel. 


\section{Chemical analysis}

After all the imaging performed, the FFB immediately transfer to laboratory for chemical analyses. First, the fruitlets separated from the FFB, and then the fruit-lets weighed and compared with the initial weight of FFB. Oil inside the fruit-lets extracted using soxhlet extractor, and the procedure followed the standard established by the Indonesian oil palm research institute [5], which agreed with previous studies [1, 12-13]. The amount of oil (OC) in each FFB sample measured by comparing weight of oil extracted and initial weight of FFB. The number then determined in percent.

\section{E. Image processing and analysis}

In order to acquire the optical features from each FFB sample, its recorded images need to be processed. In this study, the image processing software was developed using Visual Basic programming by utilizing the applicationprogramming-interfaces feature in Microsoft windows (Win32APIs). The feature is a Microsoft's core set of application programming available inside the Microsoft Windows operating systems. The required tools necessary to build the software was provided by the developer support inside the Software Development Kit (SDK). The image processing software developed by utilizing the user-friendly object-oriented programming, created a more simple and easy to use software, and limited potential error from the operators. Three images from each FFB recording, from every imaging configuration, were loaded into the software automatically and it performed image segmentation to remove non-essential parts in the image. Subsequently, the value of red-green-blue (RGB) color from each pixel in the image calculated and presented in histogram. Histogram from these three images were then averaged to find the mean value of red (R_mean), green (G_mean), and blue (B_mean) from each image. These three information ( $R$ _mean, G_mean, B_mean) were considered as optical features from the recorded $\mathrm{FFB}$.

\section{F. Modelling the FFB optical responses}

In order to select features of recorded image that can be used for FFB harvest determination, first the optical feature values from each image and its recording distance were plotted into graphs, based on its light spectrum group. Differences of image recording distance influence the intensity of light that captured by the camera sensor, thus correlated with the changes of R_mean, G_mean, and B_mean values of the images from same FFB sample. This relationship can be explained by means of linear regressions, where the correlation could be specified by equation 1

$$
y_{i}=a x+b
$$

where $y_{i}$ represents the value of $R \_$mean, G_mean, or B_mean; $\quad x$ represents image recording distance, $a$ is coefficient of $\mathrm{x}$; and $\mathrm{b}$ is offset constant.

The "a" and "b" value in equation 1 explained the relationship between the recording distance and means of $\mathrm{R}$, $\mathrm{G}$, and $\mathrm{B}$ in recorded pictures.

The FFB samples harvested at different ripeness stages, where the bunch compositions, particularly the oil content, will be depend on its physiological development [25-26].
Therefore, to explain the relationship between oil content and the "a" and "b" values from each FFB, the data were plotted in graph grouped by the lighting condition during imaging. Alteration or shift in data compared to its information of oil content may reveal the nature of FFB features, which can be used as a sign that the samples have to be harvested. The sample which showed peculiar character will be selected, and its regression line as well as its R_mean, G_mean, and B_mean values will be considered as the threshold for determination of harvest.

\section{RESULTS AND DISCUSSION}

Infrared and ultraviolet are electromagnetic spectrum which form a monochromatic light. These lights are invisible to the human eye, but not to the camera sensor. The sensor has the capability to detect parts of these lights. Therefore, even if no light or only fraction of light was visible during the FFB imaging under these lights, the reflected energy from FFB that reached the camera sensors was equable. In consequence, the images produced by camera consistently contained the recorded optical information from the FFB. Furthermore, most color camera sensor was coated by a Bayer film layer, which filtered incoming light into three color channels, namely red $(\mathrm{R})$, green $(\mathrm{G})$, and blue $(\mathrm{B})$. These colors were arranged on each transistor of the sensor, in form of an array, and if combine, will give color information to the sensor. The color information will be translated by the electronics in the camera to produce a color image. The quality of the image, as well as how the color information processed into a color image will be depend on the camera technical specification.

In this study, all the FFB's images produced by the camera were color pictures, including the image taken under UV and IR lights. The color information (R, G, and B) from these images considered as the optical properties of the FFB.

In order to utilize the color information (RGB) from the image, first the value of RGB information should be extracted by using image processing software. The software read three images from three imaging replication, and performed segmentation to exclude non-interest objects in the picture. Then, the information in the segmented image, hence the RGB, were calculated and displayed in histogram. The histogram data then processed into three main variables, namely R_mean, G_mean, and B_mean, by dividing sum of $\mathrm{R}, \mathrm{G}$, and $\mathrm{B}$ in each histogram with the image's pixel size (10 millions). These variables and their image recording distance then plotted into graphs based on its lighting during imaging. Furthermore, the data in the graphs were analyzed by linear regression. The regressions provide information of light spectrum and intensity influence to the R_mean, G_mean, and B_mean information in the image.

The color information data of the FFB images taken under UV lighting explained in the figure 1 . The figures show that the G_mean (Fig. 1b) gave lower value compared to the R_mean (Fig. 1a) and B_mean (Fig. 1c). The case continued even with changed of image recording distance. Similarly, the trend followed with images taken under visible light (Fig. 2) and IR (Fig. 3). All figures (1-3) displayed negative relationship between mean of RGB in the images with its recording distance. 
Together with the increasing wavelength of the source light in this experiment (e.g. from ultraviolet to infrared), the images of a FFB taken from similar distance displayed a decreasing trend of color value. This was clearly showed when fig. 1 and 3 were compared. Every elegtromagnetic spectrum have its own characteristics, compriseed of the wavelength, frequency, and radiance energy. All of three were interconected to each other, and every alteration from one of the component will influence the others. Changing the illumination when imaging the FFB, from ultraviolet light to visible and infrared, means that the sample was illuminated under different wavelength, frequency and radiance energy. Therefore, the reflected light from FFB captured by the camera sensor will have differences, dispite the power of light sources were similar. Since these lights have different properties, the way its transmitted through the air will be unequal to each other. Longer wavelength light tend to loose less energy when transverse through the air or athmosphere, compared to the shorter one.

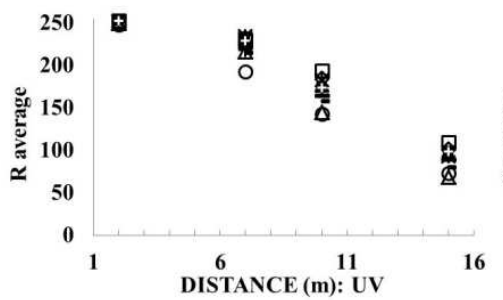

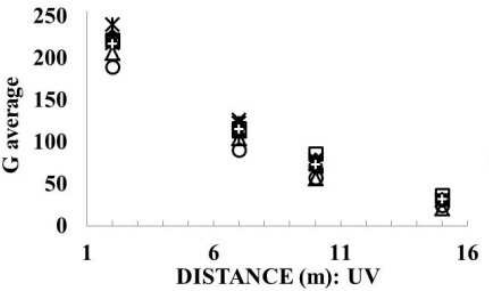

b.

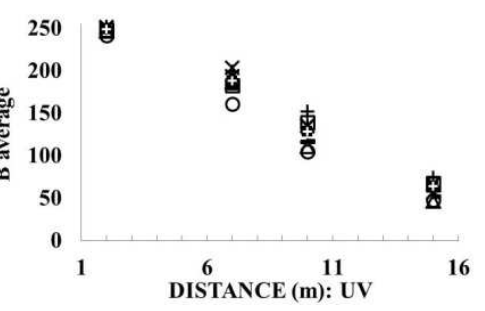

Fig. 1. The value of R_mean (a), G_mean (b), and B_mean (c) of FFB images relative to their imaging distance when lighted under 600 watt ultraviolet light.

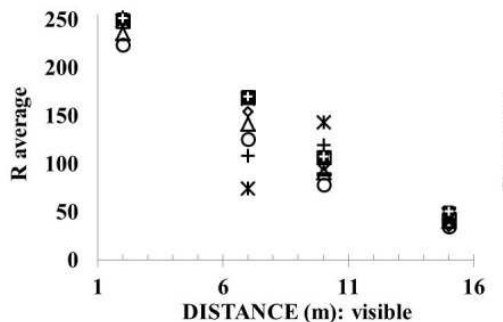

a.

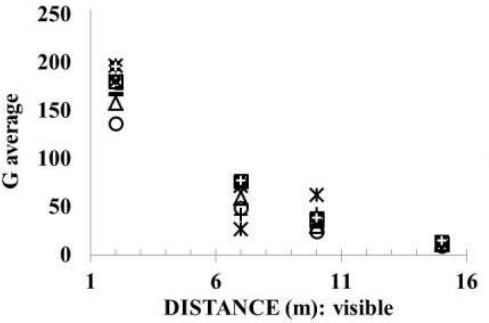

b.

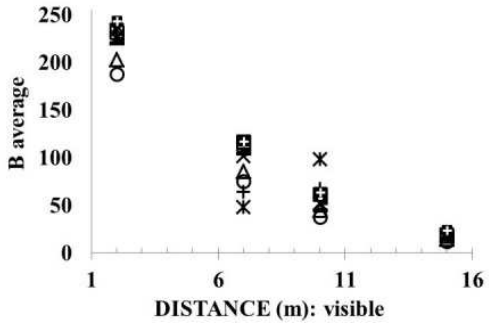

c.

Fig. 2. The value of R_mean (a), G_mean (b), and B_mean (c) of FFB images relative to their imaging distance when lighted under 600 watt visible light.

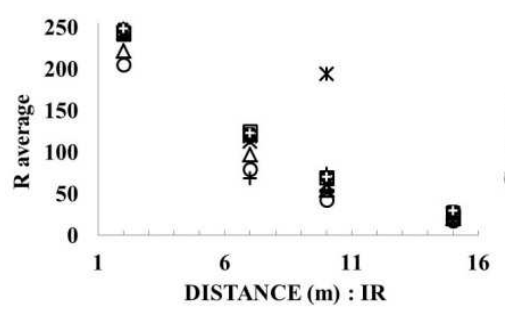

a.

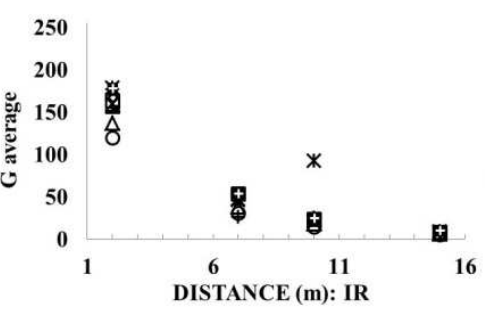

b.

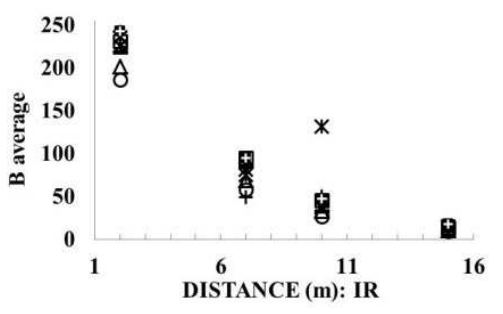

C.

Fig. 3. The value of R_mean (a), G_mean (b), and B_mean (c) of FFB images relative to their imaging distance when lighted under 600 watt infrared light.

In figure 4, the histograms of FFB images recorded under ultraviolet light displayed in chronological order, from $\mathrm{R}$ (fig. 4a), G (Fig. 4b), and B (Fig. 4c) color channels. The figures showed that the same FFB recorded from different distance displayed changes of histogram peak positions, height, and widht, from higher digital number, or commonly known as most significant bit (MSB), to the lower digital number, or least significant bit (LSB), correspondingly with the increasing recording distance, in every color channel. When illuminated with visible (Fig. 5) and infrared light (Fig. 6), the histogram from recorded images of the same FFB showed similar alteration of peaks, where it move toward the LSB by increasing FFB recording distance. In addition to the position change, the peaks became higher and narrower with the increasing of the image recording distance, as well as the lighting spectrum. The differences clearly showed when the peaks of histogram of $\mathrm{G}$ from images of FFB recorded under ultraviolet (Fig. 4b) and IR (Fig. 6b) light were compared. In contrast, less variations observed when histogram of FFB images recorded under visible (Fig. 5) and IR (Fig. 6) light being compared. The results indicate that, by increasing the imaging distance, the color of FFB images became more solid. Furthermore, increasing the wavelength spectrum of lighting during imaging will double the effect, and created much more uniform and solid color of FFB image. 


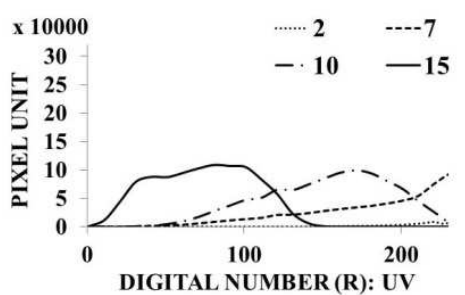

a.

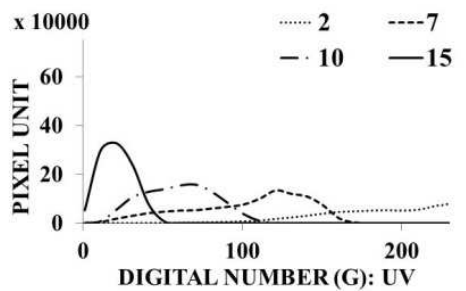

b.

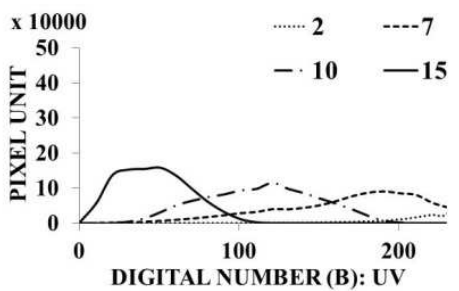

c.

Fig. 4 Change of FFB Images histogram positions, peaks height and width correspondingly to the image recording distances when illuminated with UV lights (320-380nm) for R (a), G (b), and B (c) color channels.

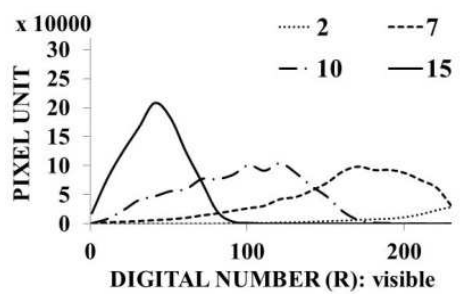

a.

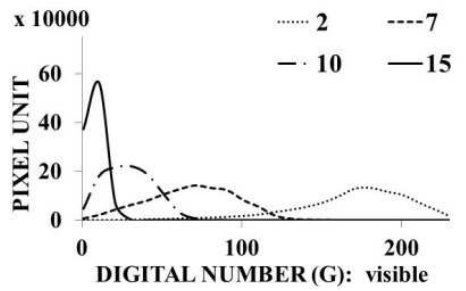

b.

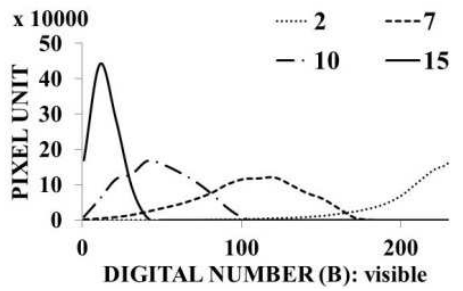

c.

Fig. 5 Change of FFB Images histogram positions, peaks height and width correspondingly to the image recording distances when illuminated with visible lights (400-700nm) for R (a), G (b), and B (c) color channels.

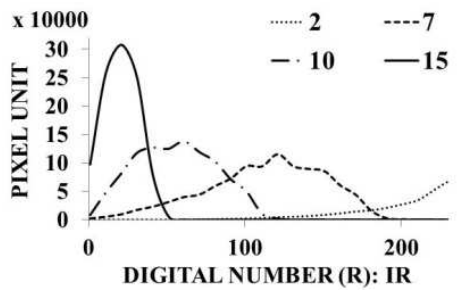

a.

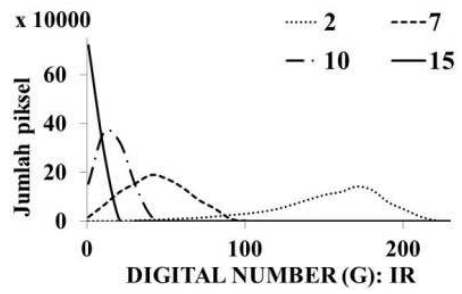

b.

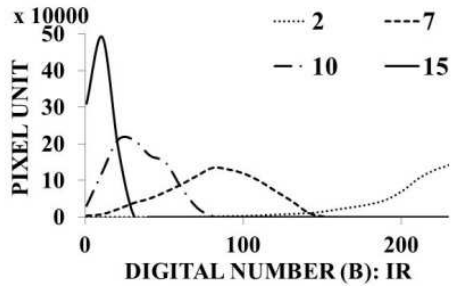

C.

Fig. 6 Change of FFB Images histogram positions, peaks height and width correspondingly to the image recording distances when illuminated with IR lights (720-1100nm) for R (a), G (b), and B (c) color channels.

Using the features of FFB images, such as the histogram characteristics, and means of $\mathrm{R}, \mathrm{G}$, and $\mathrm{B}$, the properties of FFB samples can be determined by correlating FFB image features with its properties. In order to find the correlation, first the R_mean, G_mean, and B_mean values of image should be related to the imaging distance by means of linear regression. The relationship between the recording distances and the mean value of RGB displayed in Fig. 7. The relationship for images recorded under UV light (Fig. 7a) showed that the linear regression line of $G$ (dotted-line) lie below the regression line of $\mathrm{B}$ (bold-line) and $\mathrm{R}$ (dashedline). Likewise, the regression line of images recorded under visible light (Fig. 7b) and IR (Fig. 7c). The regression line indicated the tone of relationship of two variables, namely recording distance and lighting spectrum, to the color properties ( $R, G$, and $B$ ) of recorded image. In general, the relationship was negative toward recording distance, while for the lighting spectrum, the relationship explained through the line offset and incline. Unanimously, the mean value of RGB of the image became smaller when the wavelength of light for irradiation during imaging changed increased, from UV (320-380 nm) to visible $(400-700 \mathrm{~nm})$ up to IR (720$1100 \mathrm{~nm}$ ). While the camera sensor has the ability to capture the UV and IR light, but due to the sensing limitation, only these wavelengths (320-380 nm for UV; and (720-1100 nm for IR) were taken into consideration in this study.

Every FFB produced different trend of its RGB value toward its image recording distance. It has been explained earlier, that this relationship could be determined through linear regression analysis. The Fig. 7 only represents one sample of FFB. For the rest of the samples, these relationships were presented as regression linear equations in Table 1.

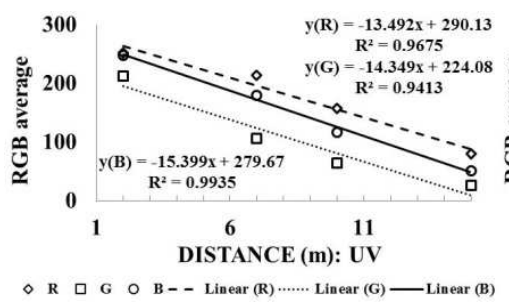

a.

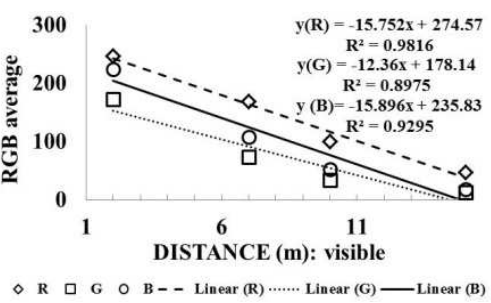

b.

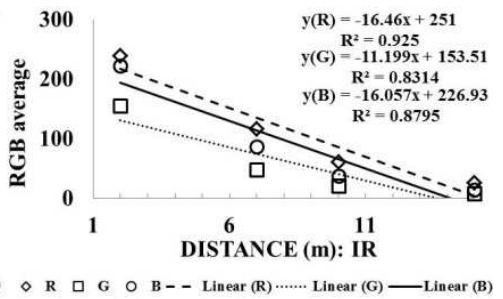

c.

Fig. 7 Relationship between mean of RGB from FFB images with its recording distance explained using linear regression model for images recorded under UV light (a), visible light (b), and IR light (c). The dashed-line (upper line) represents regression of R; the boldline (middle line) represents regression of $\mathrm{B}$; and the dotted-line (lower line) represents regression of $\mathrm{G}$. 
Results of linear regressions in Table 1 showed how FFB's color in image greatly influence by its imaging distance, spectrum of light used during imaging, and the oil contain in the FFB mesocarp, which determine the fruit's skin color in the FFB. This linear regression equation described how the optical properties of FFB sample. The optical properties mentioned can be observed by changes of linear regression inclination, or coefficient a, which indicate how much the recording distance influence the RGB color in image from recorded FFB sample. The offset value of the regression line, or the $\mathrm{b}$ constant, explained the maximum and minimum recording distance that can be applied to the FFB sample, on every color channels (R, G, and B).

From linear regression equations in Table 1 , it is showed that the $b$ value in the equation decrease when the wavelength of light used during imaging increased. This trend observed in all three color channels (RGB). The values of a in $\mathrm{R}$ color channel have positive relationship with the wavelength of light used during imaging, reciprocal with the values of $\mathrm{a}$ in $\mathrm{G}$. In contrast, the values of a in $\mathrm{B}$ did not correlated to the wavelength of light used during imaging. Therefore, the R_mean and G_mean value from the FFB images were the preferable optical values that can be used to determine the harvest of FFB.

The FFB samples in this study have different oil content, since they were harvested at different ripeness stages. The oil content of FFB sample determined by the physiological development of the fruits when harvest. The physiological development of the FFB can be observed by the change of the fruit skin color. The change occurs due to the transformation of chlorophyll pigments into carotene [12, 14-16] in the mesocarp. The carotene pigment accumulates simultaneously with the maturation process of the FFB on the tree.

The FFB is not climacterics fruits, therefore, after the bunch harvested, the fruit's physiological growth slowing down or even stop completely. Similarly, so does the ripening process and the oil accumulation in the fruit. The chlorophyll and carotene pigments contained in the organic material have a different response when irradiated by electromagnetic waves [27-28]. In this study, three types of lighting used during imaging have different features, correlated to their electromagnetic waves characteristics.

The longer wavelength of light used in this experiment, doesn't necessary mean it is more suitable to be used for FFB properties determination, i.e. its oil content. In order to identify most suitable light spectrum for determining FFB properties, the value of $a$ and $b$ of the linear regression equations from table 1 were put into graphs and grouped based on the type of light used during imaging (Fig. 8 and 9).

In Fig. 8 and Fig. 9, the value of a and the value of $b$ influenced by the type of lighting or the light spectrum use for illumination during image recording. In addition, both values were also affected by the oil content of the sample. Furthermore, in Fig. 8 and Fig.9, the value of $a$ and $b$ that significantly different were marked with "*”. Moreover, in Fig. 8b, and Fig. 9b, the value of a and b in $\mathrm{G}$ color channel from FFB sample with oil content of $21.585 \%$ significantly different from other samples. The differences observed in all three light spectrums used for FFB image recording (UV, Visible, and IR). Based on its characteristics, the optical properties of FFB image in G color channel, and sample oil content of $21.585 \%$ selected as the threshold reference for harvest decision of FFB. The selection of FFB with oil content of $21.585 \%$ correspondingly with the results from previous studies, where FFB considered as ripe and need to be harvested when its oil content is $20-24 \%$ [5,29] or $21.43 \%$ [28].

Employing the selected optical properties of the FFB with oil content of $21.585 \%$, the regression line of $G$ from this FFB, as mentioned in the Table 1, plotted into the graph together with other G_mean values from all samples as displayed in Fig. 10. The threshold line intersected with several data of the samples in several points, whether from the FFB images recorded under UV (Fig 10a), visible (Fig. 10b), or IR (Fig. 10c) light. Based on the threshold, the samples may categorize as harvest based on its $G$ optical properties. If the value of $G_{-}$mean from a sample closed to the G_mean value of FFB with oil content of $21.585 \%$, and they both placed below or above the threshold line, then the FFB sample can be consider as ripe and need to be harvested. However, this method for determining the harvest decision for the FFB sample cannot be generalized in all recording distance and in all imaging light spectrums.

In Fig. 10, all of the G_mean values, from the FFB images recorded from $2 \mathrm{~m}$, located above the threshold line. The cases occurred in all three lighting recording spectrum (Fig, 10a, 10b, and 10c). This condition indicated that FFB samples cannot be distinguished between ripe and unripe when its image recorded from the distance of $2 \mathrm{~m}$. Therefore, the harvest decision cannot be made with this imaging configuration. Likewise, the G_mean data from images of FFB recorded from $15 \mathrm{~m}$, produced similar indistinguishable results. Accordingly, this recording distance is not suitable for assessing the FFB for harvest decision. In addition, the FFB imaging with visible and IR light displayed a zero value of threshold line when it crossed the $\mathrm{x}$ axis at $13.5 \mathrm{~m}$. Consequently, this limited the maximum possible recording distance for FFB recorded under these lights.

At the time when the FFB recorded from the distance of 7 and $10 \mathrm{~m}$, the values of $\mathrm{G}_{-}$mean of the samples located in both below and upper of the threshold line in the graph. Under UV light, when the samples recorded from $10 \mathrm{~m}$, the FFB with oil content lower than $21.585 \%$ located above the threshold line, except the FFB with oil content of $13.687 \%$. The reason for this misplaced of the G_mean position, for the FFB with low oil content, possibly due to the similar resemblance of the FFB which fall within the camera point of view. For the FFB imaging under visible lighting, the images taken from $10 \mathrm{~m}$ distance have G_mean values smaller than the threshold line, except for the two samples with oil content of $24.3 \%$ and $26.223 \%$. Furthermore, the IR light use for imaging, produce images with G_mean value greater than the threshold line, except for one FFB sample with oil content of $24.3 \%$. The results indicated that recording distance of $10 \mathrm{~m}$ for the FFB imaging did not produce significant segregation to distinguish the ripe FFB from the unripe, in all three imaging spectrums. 
TABLE I

REGRESSION LINEAR MODEL EQUATION FOR MEAN OF RGB AND IMAGES RECORDING DISTANCE EXPLAINED BASED ON EQ. 1. THE A AND B VALUES IN THE EQUATION REPRESENT THE REGRESSION LINE INCLINATION AND OFFSET. THE DATA GROUPED BASED ON THE FFB SAMPLE OIL CONTENT AND SPECTRUM OF IMAGING LIGHTS.

\begin{tabular}{|c|c|c|c|c|c|c|c|}
\hline \multirow{2}{*}{$\begin{array}{c}\text { FFB Sample } \\
\text { Oil content }(\%)\end{array}$} & \multirow{2}{*}{$\begin{array}{c}\text { Imaging } \\
\text { Spectrum }\end{array}$} & \multicolumn{2}{|c|}{ Linear regression of $\mathrm{R}$} & \multicolumn{2}{|c|}{ Linear regression of $\mathbf{G}$} & \multicolumn{2}{|c|}{ Linear regression of $\mathrm{B}$} \\
\hline & & Equation* & $\mathbf{R}_{(\mathbf{R})}{ }^{2}$ & Equation* & $\mathbf{R}_{(\mathbf{G})}{ }^{2}$ & Equation* & $\mathbf{R}_{(\mathbf{B})}{ }^{2}$ \\
\hline \multirow[t]{3}{*}{13.687} & UV & $R=-12.922 x+291.14$ & 0.9579 & $G=-14.465 x+227.53$ & 0.9363 & $B=-14.829 x+276.14$ & 0.9882 \\
\hline & Visible & $R=-16.321 x+272.74$ & 0.9737 & $\mathrm{G}=-12.101 \mathrm{x}+171.98$ & 0.8930 & $B=-15.959 x+231.45$ & 0.9209 \\
\hline & IR & $R=-16.678 x+247.53$ & 0.9239 & $\mathrm{G}=-10.887 \mathrm{x}+148.04$ & 0.8353 & $B=-15.921 x+221.44$ & 0.8767 \\
\hline \multirow{3}{*}{18.419} & UV & $R=-12.151 x+291.74$ & 0.9406 & $\mathrm{G}=-14.214 \mathrm{x}+229.94$ & 0.9514 & $\mathrm{~B}=-14.495 \mathrm{x}+280.64$ & 0.9319 \\
\hline & Visible & $R=-15.681 x+278.81$ & 0.9877 & $\mathrm{G}=-13.867 \mathrm{x}+199.45$ & 0.8852 & $B=-16.906 x+255.36$ & 0.9922 \\
\hline & IR & $R=-16.898 x+261.63$ & 0.9333 & $\mathrm{G}=-12.759 \mathrm{x}+174.95$ & 0.8264 & $B=-17.276 x+247.45$ & 0.8838 \\
\hline \multirow[t]{3}{*}{20.240} & UV & $R=-11.016 x+289.74$ & 0.9207 & $G=-13.985 x+233.63$ & 0.9522 & $B=-13.917 x+277.60$ & 0.9992 \\
\hline & Visible & $R=-16.198 x+278.98$ & 0.9939 & $\mathrm{G}=-12.916 \mathrm{x}+186.36$ & 0.9104 & $B=-16.583 x+248.10$ & 0.9501 \\
\hline & IR & $R=-16.950 x+259.21$ & 0.9504 & $\mathrm{G}=-11.848 \mathrm{x}+163.13$ & 0.8502 & $B=-16.711 x+237.98$ & 0.9022 \\
\hline \multirow[t]{3}{*}{21.490} & UV & $R=-12.175 x+292.58$ & 0.9260 & $\mathrm{G}=-14.556 \mathrm{x}+236.09$ & 0.9679 & $\mathrm{~B}=-14.549 \mathrm{x}+287.15$ & 0.9766 \\
\hline & Visible & $R=-15.688 x+275.75$ & 0.9886 & $\mathrm{G}=-12.863 \mathrm{x}+184.69$ & 0.8881 & $\mathrm{~B}=-16.015 \mathrm{x}+235.59$ & 0.9197 \\
\hline & IR & $R=-16.672 x+252.15$ & 0.9192 & $\mathrm{G}=-11.501 \mathrm{x}+156.84$ & 0.8180 & $\mathrm{~B}=-16.252 \mathrm{x}+227.67$ & 0.8657 \\
\hline \multirow[t]{3}{*}{21.585} & UV & $R=-12.205 x+323.86$ & 0.9860 & $\mathrm{G}=-12.602 \mathrm{x}+197.22$ & 0.9281 & $\mathrm{~B}=-15.116 \mathrm{x}+267.29$ & 0.9903 \\
\hline & Visible & $R=-14.588 x+239.26$ & 0.9627 & $\mathrm{G}=-9.6911 \mathrm{x}+137.13$ & 0.8656 & $\mathrm{~B}=-13.454 \mathrm{x}+192.87$ & 0.8935 \\
\hline & IR & $\mathrm{R}=-14.329 \mathrm{x}+208.29$ & 0.8782 & $\mathrm{G}=-8.5914 \mathrm{x}+115.87$ & 0.7994 & $\mathrm{~B}=-13.428 \mathrm{x}+184.04$ & 0.8368 \\
\hline \multirow[t]{3}{*}{22.376} & UV & $R=-13.492 x+290.13$ & 0.9675 & $\mathrm{G}=-14.349 \mathrm{x}+224.08$ & 0.9413 & $\mathrm{~B}=-15.39$ & 0.9935 \\
\hline & Visi & $R=-15.752 x+274.57$ & 0.9816 & $\mathrm{G}=-12.360 \mathrm{x}+178.14$ & 0.8975 & $\mathrm{~B}=-15.896 \mathrm{x}+235.83$ & 0.9295 \\
\hline & IR & $R=-16.460 x+251.00$ & 0.9250 & $\mathrm{G}=-11.199 \mathrm{x}+153.51$ & 0.8314 & $\mathrm{~B}=-16.057 \mathrm{x}+226.93$ & 0.8795 \\
\hline \multirow[t]{3}{*}{23.896} & UV & $\mathrm{R}=-11.669 \mathrm{x}+293.5$ & 0.9104 & $\mathrm{G}=-14.881 \mathrm{x}+242.17$ & 0.9536 & $\mathrm{~B}=-14.723 \mathrm{x}+282.03$ & 0.9936 \\
\hline & Visible & $R=-16.506 x+274.49$ & 0.9899 & $\mathrm{G}=-13.113 \mathrm{x}+186.04$ & 0.8890 & $\mathrm{~B}=-16.691 \mathrm{x}+244.60$ & 0.9320 \\
\hline & IR & $\mathrm{R}=-17.040 \mathrm{x}+257.05$ & 0.9383 & $\mathrm{G}=-12.098 \mathrm{x}+164.54$ & 0.8330 & $\mathrm{~B}=-16.746 \mathrm{x}+234.65$ & 0.8828 \\
\hline \multirow[t]{3}{*}{23.904} & UV & $R=-14.449 x+292.53$ & 0.9563 & $\mathrm{G}=-14.300 \mathrm{x}+218.21$ & 0.9432 & $B=-15.908 x+283.13$ & 0.9814 \\
\hline & Visi & $R=-15.109 x+255.36$ & 0.9762 & $\mathrm{G}=-11.222 \mathrm{x}+159.64$ & 0.8760 & $B=-14.502 x+210.47$ & 0.9076 \\
\hline & IR & $R=-15.412 x+229.51$ & 0.9139 & $\mathrm{G}=-9.8387 \mathrm{x}+133.85$ & 0.8168 & $\mathrm{~B}=-14.546 \mathrm{x}+201.81$ & 0.8582 \\
\hline \multirow[t]{3}{*}{24.300} & UV & $R=-12.569 x+297.48$ & 0.9101 & $\mathrm{G}=-16.13$ & 0.9510 & $\mathrm{~B}=-15.210 \mathrm{x}+288.39$ & 0.9903 \\
\hline & Visi & $\mathrm{R}=-13$ & 0.6772 & $\mathrm{G}=-12.784 \mathrm{x}+183.23$ & 0.6907 & $\mathrm{~B}=-14.807 \mathrm{x}+226.02$ & 0.7185 \\
\hline & IR & $\mathrm{R}=-14$ & 0.7099 & $\mathrm{G}=-11$. & 0.7535 & $B=-15.166 x+243.10$ & 0.7769 \\
\hline \multirow[t]{3}{*}{26.223} & UV & $R=-9.0733 x+309.11$ & 0.9928 & $\mathrm{G}=-14.848 \mathrm{x}+234.83$ & 0.9238 & $\mathrm{~B}=-13.770 \mathrm{x}+286.10$ & 0.9884 \\
\hline & Visi & $R=-14.712 x+257.03$ & 0.8687 & $\mathrm{G}=-13.377 \mathrm{x}+187.14$ & 0.7664 & $B=-16.013 x+234.04$ & 0.8055 \\
\hline & IR & $R=-16.120 x+241.60$ & 0.7965 & $\mathrm{G}=-12.297 \mathrm{x}+164.09$ & 0.7216 & $B=-16.538 x+229.39$ & 0.7631 \\
\hline
\end{tabular}

*the negative values in the equation indicate that the values of mean of $\mathrm{R}, \mathrm{G}$, and $\mathrm{B}$ have negative relationship with the imaging distance of the FFB. The $\mathrm{x}$ in the equation indicate the imaging distance; the a value is the coefficient of $x$; and the $b$ value are the offset value of equation. 


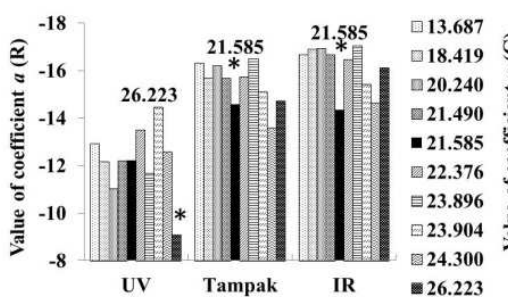

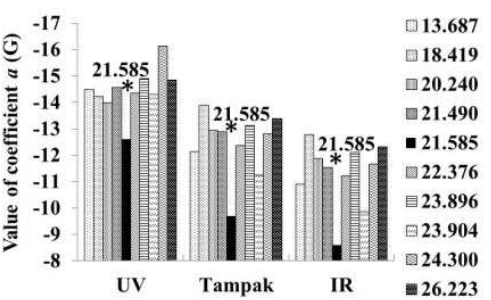

b.

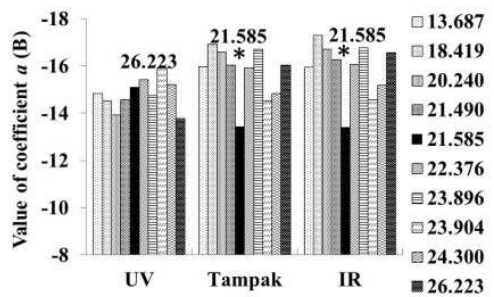

c.

Fig. 8 The value of coefficient a from the regression equation in Table 1 plotted according to sample oil content, and grouped based on the imaging spectrum. The graph presented for R_mean (a), G_mean (b), and B_mean (c).

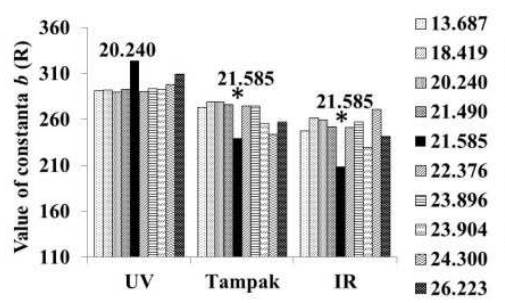

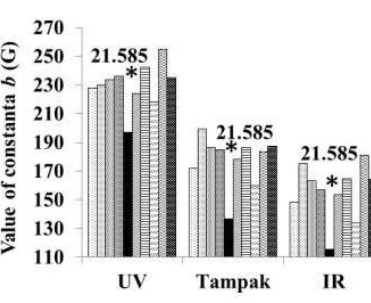

b.

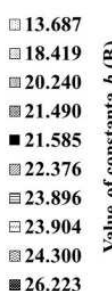

$=26.223$

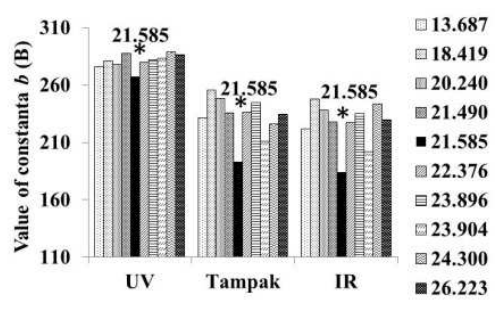

c.

Fig. 9 The value of offset $b$ from the regression equation in Table 1 plotted according to sample oil content, and grouped based on the imaging spectrum. The graph presented for R_mean (a), G_mean (b), and B_mean (c).

For the recording distance of $7 \mathrm{~m}$, the mean $\mathrm{G}$-mean values of FFB images, recorded under UV and visible light, delivered results that can be used to segregate the ripe and unripe samples. Therefore, the most suitable imaging configuration to determine the FFB ripeness based on its oil content for harvest decision is to record FFB image from $7 \mathrm{~m}$ using UV or Visible light. Moreover, the optical feature of FFB that can be used to distinguish a ripe FFB for harvest decision according to its oil content is the greenish of the fruits skin, illuminated with UV or visible light, and recorded using camera from $7 \mathrm{~m}$.

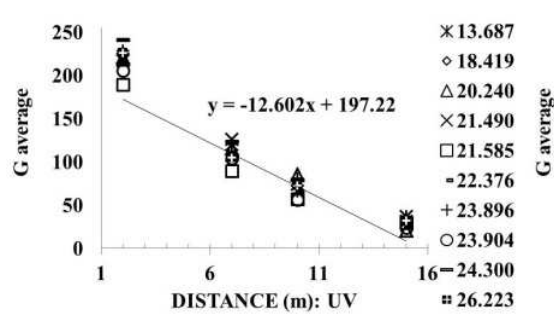

a.

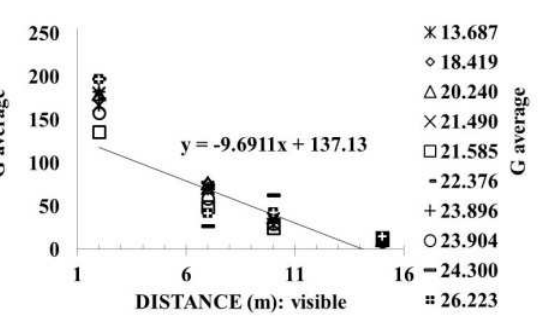

b.

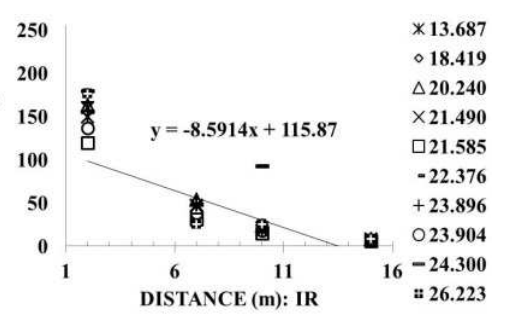

c.

Fig. 10 Threshold line for harvest decision based on the regression equation from FFB sample with oil content of $21.585 \%$. The optical property of FFB under consideration is the G_mean from recorded images. The value of G_mean placed above the line indicated the FFB for harvest

The threshold line in Fig. 10 is the linear regression equation of FFB with $21.585 \%$ of oil content based on the relationship between its G_mean and Recording distance. The line functioned as the boundary for segregating ripe and non-ripe FFB based on its $G$ _mean value from their image, recorded from $7 \mathrm{~m}$. The harvest decision of FFB performed through a comparison of $G_{-}$mean value from the sample with the $G$ mean value from the threshold. The threshold line for UV lighting crossed the point of 109.006 at $7 \mathrm{~m}$, based on its $\mathrm{G}$ regression line equation in Table 1, which is $\mathrm{G}=-12,602 \mathrm{x}+197.22$. For the threshold line of visible light, the line crossed at 69.292 at $7 \mathrm{~m}$ based on the equation in Table $1(G=-9,6911 x+137.13)$. These values of $G \_$mean became the threshold for all the FFB assessment, for instance, when a FFB examined using same imaging configuration, then if its $G_{-}$mean value smaller than threshold, then the corresponding FFB shall be consider as ripe and will be harvest.

\section{CONCLUSIONS}

In this study, the FFB optical properties were studied by recording the samples under different light spectrums, and recording distance variations. In addition, the FFB samples came in different ripeness, as well as its oil content. The optical properties of FFB identified through the color information from the recorded images. The image color information comprised of three color channels, namely R, G, and $B$. Through image analyses by means of image processing software, the $\mathrm{R}, \mathrm{G}$, and $\mathrm{B}$ information in image can be extracted and converted into histogram. The histogram then averaged and the results (mean of R, G, and B) compared with imaging distances to produce linear regression. The coefficient value of all linear regression 
from samples were correlated to the sample's oil content and grouped according to the lighting spectrum used during imaging. The sample with significant contrast was selected as the threshold basis using its regression line. The selected FFB for threshold was the sample with oil content of $21.585 \%$. The optical feature selected for threshold comparison was the G_mean from the image. The threshold in this study can distinguished the ripening stages of FFB samples and its harvest determination, which correlated to their oil content by recording the sample images from $7 \mathrm{~m}$ under UV or visible lights. Harvesting the FFB can be decided whenever the images of observed sample have the G_mean value lower than 109.006 or 69.292 when it is recorded from $7 \mathrm{~m}$ under UV and visible light, respectively.

The potential for applying this study results is vast, due to the rapid growth of oil palm plantation area in Indonesia [30]. A further study is required to explore the methods for FFB harvest decision through its ripeness and oil content assessment from closer or farther distance.

\section{ACKNOWLEDGMENT}

The first author expresses their noble gratitude to PT. Astra Agro Lestari, DP2M Dikti, Bogor Agricultural University, and DIKTI for providing funding for this research and doctoral scholarship.

\section{REFERENCES}

[1] Makky M., Herodian S., Cherie D., Ahmad U., and Mandang T. 2012a. Spectroscopy and Photogrammetric techniques for assessing physicochemical properties of oil palm (Elaeis guineensis Jacq) Fresh Fruits Bunch (FFB). Proc. Research Dissemination Seminar, International Convention Center (IICC) - Bogor Agricultural University,, Bogor, 10-11 December, Indonesia.

[2] Makky M., Soni P., and Salokhe V.M. 2012b. Machine Vision Application in Indonesian Oil Palm Industry. The Asian Forum of 2012 CSAM (Chinese Society for Agricultural Machinery) International Academic Annual Meeting. "Innovation, Win-win, Development". October 27th -30th, Hangzhou, China.

[3] Dirjend PPHP. 2014. Agricultural goods import export statistic 2011 - 2013. J. of Agricultural goods import export statistic, Ministry of agriculture. (in Indonesian) ISSN 2337 - 9578.

[4] GAPKI. 2014. Oil palm Industry Reflection in 2013 and the 2014 prospects. GAPKI, Press Release at http://www.gapki.or.id/Page/PressReleaseDetail?guid=d414bf22e99e-4cbd-9305-1deb5d019f4e, accessed on 15 Januari 2014 (in Indonesian).

[5] IOPRI. 1997. Palm oil and palm oil mill waste management. Standardization team for palm oil processing. Indonesian Oil Palm Research Institute (IOPRI) (in Indonesian). Directorate general of forestry, Indonesia.

[6] Ikemefuna, J., Adamson, I. 1984. Chlorophyll and carotenoid changes in ripening palm fruit, Elaeis guineensis. Phytochemistry, 23: 1413-1415.

[7] Tan, Y.A., Chong, C.L., and Low, K.S. 1997. Crude palm oil characteristics and chlorophyll content. J.Science of Food and Agriculture, 75: 281-288.

[8] Sambanthamurthi, R.K., and Tan, Y. 2000. Chemistry and biochemistry of oil palm. Progress in Lipid Research, 39: 507-558.

[9] Makky M., Herodian S., and Subrata I.D.M., 2004. Design and Technical test of visual sensing system for palm oil harvesting robot. Proc. Int. Seminar on Advanced Agric. Eng. Farm Work Operation, August 25-26, Bogor, Indonesia.

[10] Makky M. and Soni P., 2013a. Towards sustainable green production: exploring automated grading for oil palm fresh fruit bunches (FFB) using machine vision and spectral analysis. Int. J. Advanced Sci. Eng. Information Technol., 3(1), 1-7.
[11] Makky M. and Soni P., 2013b. Development of an automatic grading machine for oil palm fresh fruit bunches (FFBs) based on machine vision. Computers Electronics Agric., 93, 129-139.

[12] Makky M. and Soni P., 2014. In situ quality assessment of intact oil palm fresh fruit bunches using rapid portable non-contact and nondestructive approach. J. Food Eng., 120, 248-259.

[13] Makky M., Soni P., and Salokhe V.M., 2014a. Automatic nondestructive quality inspection system for oil palm fruits. Int. Agrophys., 28, 319-329.

[14] Makky M., Paschalidis K.A., Dima K., and Mangganaris A. 2014b. Harnessing Untapped Bio-Ethylene Sources from Tomatoes Climacteric Effluent. Proc. International Conference on Agricultural, Environmental and Biological Sciences (AEBS-2014) April 24-25, Phuket, Thailand. pp. 27-32.

[15] Makky M., Paschalidis K.A., Dima K., and Mangganaris A. 2014c. A New Rapid Gas Chromatographic Method for Ethylene, Respirational, and Senescent Gaseous Production of Climacteric Fruits Stored in Prolonged Low Temperature. Proc. International Conference on Agricultural, Environmental and Biological Sciences (AEBS-2014) April 24-25, Phuket, Thailand. pp. 21-26.

[16] Makky M., Paschalidis K.A., Dima K., and Mangganaris A., 2015. Tomato Fruits (Solanaceae Lycopersicon esculentum Mill.) Feedback Mechanism in The Presence of Exogenous Ethylene under Prolonged Chilling Temperature Storage. Journal of Nutrition \& Pharmacy Research, 1(1):4-12. International Institute of science and industry research, Australia.

[17] Abdullah, M.Z., Guan, L.C., and Mohamed A.M.D. 2001. Stepwise discriminant analysis for color grading of oil palm using machine vision system. Transaction of Institute of Chemical Engineering: Part C, 79: 223-231.

[18] Abdullah, M.Z., Guan, L.C., Mohamed A.M.D., and Noor, M.A.M. 2002. Color vision system for ripeness inspection of oil palm (Elaeis Guineensis). J Food Processing Preservation 26:213-235.

[19] Abdullah, M.Z., Guan, L.C., Limand K.C., and Karim, A.A. 2004 The applications of computer vision system and tomographic radar imaging for assessing physical properties of food. J. Food Engineering, 61: 125-135.

[20] Alfatni, M.S.M., Shariff, A.R.M., Shafri, H.Z.M., Saaed, O.M.B., and Eshanta, M. 2008. Oil palm fruit bunch grading system using red, green and blue digital number. J. Applied Sciences, 8: 14441452 .

[21] Ismail, W.I.W., Razali M.H., Ramli, A.R., Sulaiman, M.N. dan Harun, M.H.B. 2009. Development of imaging application for oil palm fruit maturity prediction. Engineering e-Transaction (ISSN 1823-6379), 4: 2 (56-63).

[22] Saeed, O.M.B., Sankaran, S., Shariff, A.R.M., Shafri, H.Z.M., Ehsani, R., Alfatni, M.S., and Hazir, M.H.M. 2012. Classification of oil palm fresh fruit bunches based on their maturity using portable fourband sensor system. J. Computers and Electronics in Agriculture, 82: 55-60. Elsevier.

[23] Junkwon, P., Takigawa, T., Okamoto, H., Hasegawa, H., Koike, M., Sakai, K., dan Siruntawineti, J., Chacychomsri, W., Vanavichit, A., Tittinuchanon, P., Bahalayyodhin, B. 2009. Hyperspectral imaging for nondestructive determination of internal qualities for oil palm (Elaeis guineensis Jacq. Var. tenera). Agricultural Information Research, 18 (3): 130-141, JSAI.

[24] Roseleena, J., Nursuriati, J., Ahmed, J., and Low, C.Y. 2011 Assessment of palm oil fresh bunches using photogrammetric grading system. J. Food Research, 18 (3): 999-1005.

[25] Arrifin, A.A., Soom, R.M., Banjari, M., and Omar, W.Z.W. 1990. Morphological changes of the cellular component of the developing palm fruit. PORIM, Bull.: 21, Kuala Lumpur.

[26] Balasundram, S.K., Robert, P.C., and Mulla, D.J. 2010. Relationship between oil content and fruit surface color in oil palm (Elaeis guineensis Jacq.). J. of Plant Sciences 5 (3): 298-308.

[27] Ketaren, S. 1986. Introduction to fats and edible oil technology. (in Indonesian) UI Press, Jakarta.

[28] Puspitasari, T. 2002. Synthesis emulsifiers from oil palm fresh fruit bunches ( FFB ) in different ripeness using in situ lipase enzyme. Thesis. (in Indonesian) Bogor Agricultural University, Bogor.

[29] Lubis, A.U. 1998. Oil Palm in Indonesia. Indonesian Oil Palm Research Institute (IOPRI). (in Indonesian). ISBN: 978-979-852987-0.

[30] USDA. 2015. Indonesia Oilseeds and Products Annual Report 2015. Gain report number: ID 1508, 20 Maret 2015. USDA. 